\title{
Unresolved Feelings of Guilt and Shame in the Maternal Role With Substance-Dependent African American Women
}

\author{
Joanne T. Ehrmin
}

Purpose: To identify care needs of A frican A merican women residing in an inner-city transitional home for substance abuse, with the goal of facilitating their ability to move successfully through treatment and recovery.

Design: Ethnography. The convenience sample consisted of 12 key participants and 18 general participants. D ata were collected 1996-1998.

M ethod: Participant observation and focused interviews were used to collect data. Participants were asked open-ended questions designed to determine their care needs as they experienced treatment and recovery for substance abuse.

Findings: U nresolved feelings of guilt and shame associated with perceptions of failure in the maternal role during their active addiction were discovered to be critical issue and possible barrier to successful treatment for African American women in a residential program for treatment of substance abuse.

C onclusions: U nresolved feelings of guilt and shame associated with consequences of the use and abuse of substances, particularly with perceptions of failure in the maternal role, could serve as barriers to successful treatment and recovery for substance-dependent African A merican women. N ursing actions designed to facilitate healing with these women could offer the potential for improved maternal and child health and well being.

Journal of Nursing ScholarShip, 2001; 33:1, 47-52. 2001 Sigma Theta Tau International.

[Key words: ethnography, African A merican women, recovery, substance abuse, parenting, guilt, shame, spirituality]

Treatment for substance-dependent women has been based on a view of the women as " weak-willed persons who cared little for the disgrace they had brought upon themselves and their families" (Valentich, 1982, p. 14). Yet fear of losing their children is one of the main reasons women seek treatment (Klee, Schmidt, \& A mes, 1991). Female substance abusers have also been labeled as psychologically deviant, hopeless, social misfits, and pathological users (Boyd \& Guthrie, 1996; Boyd, Henderson, Ross-Durow, \& Aspen, 1997; and Henderson \& Boyd, 1997) when compared to their male counterparts.

$\mathrm{H}$ igh rates of recidivism have been identified as a major health concern in treating substance-dependent clients, with relapse rates ranging from $25 \%-50 \%$ of those admitted for treatment (Llorente Del Pozo, Gomez, Fraile, \& Perez, 1998; $\mathrm{H}$ artwell, 1998). Women have been found to havelower selfesteem and poorer self-concept than do their male peers (Boyd \& Guthrie, 1996; H enderson \& Boyd, 1997; M ynatt, 1998; and R osenbaum, 1981). Knowledge about this phenomenon is limited, yet inadequate psychological support is one of the leading causes that "Black women are more likely to suffer relapses after completing alcohol treatment" (Battle, 1990, p. 252). A higher prevalence of "escape alcoholism" has been found among Black women than in other cultural groups of women, described by Battle (1990) as drinking to numb the pain from the numerous grief experiences encountered by Black women throughout their lives. Only in recent years have female substance abusers, particularly diverse cultural groups of women such as African American women with increasingly high rates of recidivism, been recognized as a vulnerablepopulation with specific needs to movesuccessfully through treatment for substance abuse.

Although a report published by the Public H ealth Service Task Force on Women's H ealth Issues (1985) recommended that efforts be made to gain knowledge about alcohol and drug-related problems among women, with particular attention to issues of family and culture, minimal research has been conducted in this area. This ethnographic research study was designed to identify care needs of A frican A merican

Joanne T. Ehrmin, RN, PhD, Postdoctoral Research Fellow, University of Michigan, School of Nursing, Ann Arbor, Ml. Correspondence to Dr. Enrmin, 400 N. Ingalls, Ann Arbor, Ml 48109-0482. E-mail: jehrmin@umich.edu Accepted for publication July 24, 2000. 
women residing in an inner-city transitional home for substance abusers to facilitate their ability to move successfully through treatment and recovery.

\section{Background}

Early studies of mothers who used alcohol and drugs were conducted to identify their ability to adequately perform mothering skills, including their underlying parenting beliefs and attitudes, while actively using al cohol and drugs. Findings included information that addicted and nonaddicted mothers held similar beliefs and attitudes about the maternal role, including the high value they placed on that role (Kearney, M urphy, \& Rosenbaum, 1994; Wellisch \& Steinberg, 1980).

Frequently, women entering treatment programs have been forced to place their children with family members when possible, or as a last resort, in state-funded foster care. Either situation can magnify existing negative beliefs about the self, particularly in relation to feelings of guilt and shame associated with perceptions of inadequacy with their mothering capabilities. Kearney and colleagues (1994) discovered that women who lost custody of their children, voluntarily or involuntarily, frequently increased drug use to deal with their loss. Yet the psychological implications of the women following the loss of their children were not identified.

Women in general have been socialized to repress, rather than express, feelings of anger, inadequacy, and guilt, and those women at high familial risk for substance abuse have attempted to deal with unacceptable feelings by using alcohol and drugs (Boyd, H enderson, R oss-Durow, \& Aspen, 1997; Henderson \& Boyd, 1997; Woodhouse, 1990). Blume(1990) said that the disapproving societal stigma attached to female substance abusers fosters an intense guilt and shame based on beliefs about the self, and keeps these women "in hiding" (p. 299). H atton (1997) identified shame as one of the most salient conditions in managing health problems for homeless women with children living in transitional shelters. O ne source of shame identified for study participants included "years of drug and alcohol abuse" (p. 35). Although both researchers identified feelings of guilt and shame experienced by female substance abusers in relation to their use and abuse of substances, information about perceptions of their maternal role was not identified.

In African families, "M otherhood is the ultimate greatness and nobility of a woman's life" (M ontilus, 1989, p. 11). For African women, providing emotional and physical care is highly valued. Some writers believe that this A frican heritage has been retained by A merican women of African ancestry (Collins, 1991; W hite \& Parham, 1990). African A merican women continue to take children into their care and are considered to be important figures in African American communities. But substance abuse among A frican A merican women has accelerated to epidemic proportions, possibly related to the belief that "through substance use, women temporarily lift the weight of a hostileworld" (Ettorre, 1992, p. 156).
Although research with substance-dependent women has increased in the last 10 years, little is known about the care needs of women from the perspective of the women themselves, particularly mothers, as they experience treatment and recovery for their substance abuse. M inimal research has been conducted that could facilitate the health and well being of substance-dependent women and their children, particularly with vulnerable populations such as A frican A merican w omen with alarming rates of recidivism. This research was conducted to study treatment issues of female substance abusers, particularly minority women such as African A merican women.

\section{Methods}

An ethnographic qualitative research design was chosen for this study to identify the meanings and expressions of culture-specific care as expressed by the women themselves. The researcher spent approximately 3 years at an inner-city transitional home for substance abuse, a large old home in the downtown area of a U.S. M idw estern city. R equirements for admission to the home were that women be 18 years of age or older, homeless at the time of admission, willing to participate in the community-based substance abuse treatment program, and willing to maintain mandatory abstinence from drugs and alcohol. Women were admitted to the home one time only, with no readmissions permitted. Strict rules and regulations included curfew, attendance at 12-step meetings, house chores, and prescribed patterns of communication among women and staff. If a woman had a second incident of drug or alcohol use, she was discharged. The women's children, aged 12 and younger, were allowed to live in the home. Two of the women, each with one child older than 12 , had temporarily placed their children with other family members.

A convenience sample of 12 key and 18 general participants was selected for this study. Key participants were substancedependent African A merican women either currently or formerly having lived in the transitional home. Key participants were the most know ledgeable about the domain of inquiry and expressed the norms and values of the culture under study. A purposive sample of general participants was selected from African American women in the community, including some of the staff working in the home, but never having resided in the home. 0 ne general participant was the sister of a key participant. General participants were not as fully knowledgeable about the domain, but they added perspectives to the study.

Key participants ranged in age from 23-44 years, had an educational background of 10 th grade to 2 years of college, and had one to five children between the ages of 6 months to 24 years. Seven women had custody of their children. Two women had permanently lost custody to the children's father, and two women had children in custody of other family members. O new oman, who had relapsed at the home, had three children who were placed in foster care as a last 
resort. $\mathrm{N}$ ine of the women had never been married, two were currently married, and one woman was divorced. All key participants were from socioeconomically disadvantaged backgrounds. Key participants' drugs of choice were crack (8), heroin (2), cocaine (1), and combined alcohol and crack or cocaine (1). All of the women began using alcohol or marijuana at age 13-19, and then progressed to their drug of choice at age 17-30.

Initially, the women were cautious around the researcher. Eventually the researcher was able to develop a trusting relationship with thestudy participants, a phase referred to by Leininger (1991) as moving from a stranger to a trusted friend, and by Spradley (1979) as establishing rapport to allow for the "free flow of information" (p. 78). Ethnographic techniques of participant observation and focused unstructured interviews based on an open-ended questionnaire designed for this study were used to collect data. Q uestions were structured to elicit the care needs of the women as they experienced treatment and recovery for substance abuse.

Key participants were interviewed by the researcher one to five times and general participants were interviewed one to two times. Interviews were audiotaped and transcribed verbatim by the researcher to preserve the vernacular and the meaning-in-context of the participants; over 1,000 pages of transcribed data were obtained. Each participant was assigned a number to protect and maintain anonymity. In addition to conducting formal interviews, the researcher participated in many activities with the women, including cooking and eating meals with them and their children, attending house and 12-step meetings, and celebrating birthdays and other events. N umerous informal interviews were conducted during the various activities.

Trustworthiness of findings was assured through the use of Leininger's (1991) four phases of data analysis: (a) documenting raw data, including the use of a field journal to record detailed verbatim participant and observational data and researcher dialogue, theoretical speculations, feelings, and contextual data; (b) identifying and categorizing verbatim descriptors; (c) identifying patterns and contextual analysis; and (d) identifying major themes and theoretical formulations.

\section{Findings}

Three patterns were identified indicating the values and beliefs of the 12 key and 18 general participants regarding their unresolved feelings of guilt and shame in the maternal role: perceptions of mothering, courage to face the pain, and healing the guilt and shame/forgiven for past "mistakes."

\section{Perceptions of Mothering}

The women's verbatim descriptions included many references to feelings of guilt and shame, particularly related to their perceptions of mothering during their active addiction. The women talked about realizing that their addiction was out of control and that they were causing undue pain and hardship to others, particularly their children. O ne woman's hopel essness and despair was evident when she said, "I called my auntie and told her I was draggin' em through the horrors of my addiction. I had lost so much already. $\mathrm{M}$ y kids had been tooken away."

O ne woman talked about her feelings of guilt and shame for not being there for her daughter. She said: "M y mother and father raised her." She described one experience that was particularly painful for her, when she couldn't be "trusted" to care for her own child:

\begin{abstract}
I 'member one time I was to stay with my daughter 'til my sisters came home from school. I hadn't had my fix yet and I went over to watch my baby. M e and my boyfriend stayed across the hill from my parents house. She was asleep, so I walked across the hill thinkin' maybe he had got something, but I never went back. M y sister said when she came home, my baby seemed like she had been cryin' for hours, so I had left her about 6 hours by herself. I had a lot a guilt about that.
\end{abstract}

In describing the pain they had caused their families throughout their active addiction, the women recounted frightening experiences reminiscent of a time they were desperately trying to resolve. O ne woman described the chaos for everyone involved, including herself and her family: "I was running the streets, leaving the kids 3 days at a time. They put 'em in foster homes ... then my auntie took care of 'em for 18 months for me."

Several study participants had willingly sought admission to the home as a means to maintain custody of their children, indicating that the Children's Services Board (CSB) had mandated that the women get treatment or face permanent placement of their children in state-funded foster homes. According to one woman: "CSB took my kids and was gonna take 'em permanently. They weren't supposed to give me my kids back."

All of the women had been pregnant at some point during their active addiction, and eight of the women gave birth to babies testing positivefor drugs. O nekey participant described her negligence with her children during her drug use:

\section{Doctor asked me when was the last time I used and I told him that morning, and he said promise me you gonna come back this evening so I can take the baby, cause you gonna end up killin' it.... M y baby was born that next day and he tested positive to crack and cocaine, so the hospital social worker had to call CSB and they seen that my [oldest] son didn't get his medicine, so I got a charge of neglect.}

O ne participant talked about prostituting for drug money while she was pregnant and the pain she had caused her baby by getting "high." "Do you know I didn't have the decency to think I'm killin my baby?" A nother woman talked about the hopelessness she had felt during her active addiction, that she was not able to stop using, even while she was pregnant. She described overwhel ming feelings of guilt and shame over the death of her first baby: "I got pregnant with my oldest son who died. I did use with him, cause at that time I didn't know nothin' about addiction. I couldn't help I was pregnant. I couldn't quit." 


\section{Courage to face the pain}

As the women talked about consequences of their drug use, they began to realize the enormity of the task of facing their pain, previously "managed" with the use of alcohol and drugs. A common theme was stated well by one who said, "I feel a lot of guilt for a lot of things that I've done." A nother described difficulty in facing her pain: "W hen I kept going back out, it was because I didn't want to look down in here (points to heart) and I didn't want to look at all the things that I had done to him [her son]."

Women were at times rendered hopeless as they gained a heightened sense of personal awareness and insight. One general participant talked about the intense feelings of guilt many of the women experienced when they began to look at themselves and their alcohol and drug abuse in relation to their loved ones, particularly their children. She said: "They may start feelin' guilty, and if they start feelin' guilty, then they gonna want to turn to a bottle or to the drugs." As the women began to realize the extent to which they had caused emotional and physical pain for loved ones, they sought strength and courage to face the pain without resorting to alcohol and drugs as they had done in the past.

For several participants, a devastating consequence of exchanging sex for drugs was pregnancy and the uncertainty of knowing the identity of the baby's father. O ne woman cried as she talked about the consequences of prostituting for drugs: "What am I gonna tell him when he get older? That he came from a date and I don't know who his father is." A nother woman said: "The alcohol hel ped mefeel numb. I felt no feelings. I felt no guilt but I couldn't talk about my kids. There was too much pain."

$\mathrm{N}$ ine of the women had lost custody of their children, either temporarily or permanently. For those women who had not lost custody, "the lucky ones," family had cared for their children during their active addiction and they were reunited with their children after moving into the home. O ne participant described her feelings of guilt and shame in losing custody of her children: "H ow am I s'posed to be a good mother and I did this to my kids? I let them get taken away from me, cause of these drugs. I put these drugs 'fore I put my kids."

Three participants talked about having been forced, through CSB, to permanently give up custody of their children to family members, because of their drug and alcohol abuse, and having madea "life-long mistake." In this system, fathers have the first choice for custody and if the father does not want the children other family members are contacted regarding child placement. O ne woman described having given up custody of her daughter to the baby's father as the most devastating consequence of her drug use: "I put her with him 'cause I wanted to go use so I could get high. I got to live with this for the rest of my life."

The women experienced a great deal of emotional pain about their difficult relationships with their children. They seemed confused about their children's anger, now that the women were sober and currently in drug treatment. O nekey participant described her pain about her son in relation to her struggle to remain clean and sober:
I have a 15 year-old son. I'm tryin' to get off drugs and tryin' to maintain my head, and he hates me, but he loves me still, but he hates me. He don't understand why he hates me, he just know he hates me. M y mother raised him. I didn't start usin' drugs 'til he was 8 or 9 years old. $N$ ine years $0^{\prime}$ his life I wasn't there.

O ne woman talked about her pain with her son's unrelenting anger concerning her drug use. She said, "I miss my son. I don't talk about him much 'cause it hurts. Last time my son with me, he called me a dope fiend. H e wanted to hit me. He was so mad at me." Another woman talked about the time her oldest son had come to the home to visit her, and her realization that he didn't "trust" that his mother would stay clean. She said:

O ne weekend he had came here, and he said "mom can you stop doin' drugs," and I say yeah and this when he wrote this [card] and he say how do you spell I hope you mean it? I told my oldest son, I didn't mean to hurt you like that [she began to cry].

All key participants in this study talked about the pain of the consequences of their drug and alcohol abuse. They experienced overwhelming feelings of guilt and shame about themselves as women and especially about themselves as mothers. Thew omen sought the courageto face the emotional pain they had caused their families, particularly their children, during active addiction.

\section{Healing the guilt and shame}

All 12 participants said they had caused their children a great deal of pain, and had caused emotional scars that required healing. As the women began the process of healing their pain, the influence of their religious and spiritual beliefs became more pronounced. The need to connect with their "higher power," which many of the women called God, became more apparent as the healing progressed.

Forgiven for past "mistakes." The women talked about unconditional love from their "higher power," and said they believed God or Jehovah had not only forgiven them but also loved them through their active use of alcohol and drugs. "Today I know the only love I got is God, 'cause He gonna love me no matter what I do." Another woman said, "In my addiction, I had forgotten there was a God. Today, I know He hadn't forgotten me." N ot being judged, and being forgiven for past "mistakes," were integral parts of care for the women.

All key participants expressed feelings of guilt and shame for what they had doneto others during their activeaddiction. The women expressed a need for staff, other health care providers, family, friends, and God to look beyond their past behaviors, and reach out to them unconditionally. Thew omen clung to hopes that their children would forgive them and love them unconditionally. O ne participant talked about her daughter's unconditional love: "I knew she would always love me, despite the fact that I was strung out, or raped, or that I sold myself ... 'cause I'm her mother." In describing an unconditionally loving God, the women expressed hopethat they could let go of the past and begin to look forward to the future. "When they talk about God and love, I know He 
loves me, and don't nobody else loves me, He will, and I know He gonna work somethin out for me, and that gives me hope."

The women repeatedly expressed gratitude to be in a safe environment and reunited with their children in the transitional home. The w omen yearned for forgiveness, even though they tended to believe they were not worthy of being forgiven. O ne general participant who worked in the home talked about her own shame and guilt in losing permanent custody of her children "to alcohol and drugs," and the need to let go of those feelings in order to maintain sobriety:

\begin{abstract}
For a lot a women in recovery who can't let go o' that shame, remorse, and guilt, they will go back out and use drugs because they feel so bad. They don't feel like it's worth it, and a lot o' ladies talks to me when they lose they kids because I been in the program the longest and still don't have my kids. The judge told me she ever seen me in court again, she make sure I don't get 'em back. But $\mathrm{He}$ [God] allowed 'em back in my life after 6 years in recovery. The lady [foster mother] has enough compassion through God touchin' her heart, she let me see 'em.
\end{abstract}

\section{Discussion}

Findings in this study indicated that a critical issue and possible barrier to treatment for African American women residing in an inner-city transitional home for substanceabuse was unresolved feelings of guilt and shame associated with perceptions of failure in the maternal role, particularly during their active addiction. According to Rowe and Grills (1993) expression of emotions is a key to working with African A mericans based on their cultural values and beliefs that "emotions are the sacred path to one's soul" (p. 29). Battle (1990) described the importance for crack-dependent A frican American women to increase their ability to recover by "eliminating feelings of alienation, oppression, despair, and low self-esteem from the inside out" (p. 254). Freire (1970/ 1990) discussed the importance of working "with," rather than "for" or "about," people in an "incessant struggle to regain their humanity" (p. 33).

The experiences of these women occurred in the social context of motherhood, regarded as nurturing children and providing emotional and physical support necessary for survival. That norm is strong in African American communities (Collins, 1991). To develop successful treatment programs for substance-dependent A frican A mericans, Battle (1990) identified theimportance of considering " the culture, lifestyle, and attitudes of the Black community" (p. 254). Culturally sensitive treatment strategies are needed in working with substance-dependent clients from diverse cultural groups. Rowe and Grills (1993) identified the need to have substance-dependent African American treatment relationships based on "reciprocity, equality, and respect" rather than being "objective, distant, and removed" (p. 26).

Limitations of the current study included the small sample size and the inability to generalize findings to other substancedependent African American women. Further research is needed to identify whether substance-dependent women from diverse cultural groups experience similar feelings of guilt and shame, particularly with respect to perceptions of failure in the maternal role.

Further research is warranted to explore whether factors such as income, education, occupation, and family support mediate both substance dependence and substance-abuse treatment and recovery. Finally, in an effort to decrease high rates of recidivism, research is needed to identify barriers to women's ability to successfully experience treatment and recovery for substance abuse. Q ualitative outcome analysis (M orse, Penrod, \& H upcey, 2000) would be useful for building on this study to extend the focus from understanding the phenomenon of unresolved feelings of guilt and shame with substance-dependent African American women regarding perceptions of failure as mothers, to a focus on nursing interventions and outcomes.

\section{Conclusions}

$O$ ver the past decade, high rates of recidivism for substancedependent women, particularly in diversecultural groups such as A frican A merican women, has been recognized as a major health problem. Historically, substance-dependent women have been "silenced" by health care providers who have tended to blame the women for their violation of societal norms concerning substance abuse.

Findings of this study indicate the need for nurses to reach out to substance-dependent African American women, to listen to the women, and to facilitate their resolution of feelings of guilt and shame associated with consequences of use and abuse of substances, particularly with respect to their perceptions of failure in the maternal role. By reaching out to these women, not only during their active addiction, but also as they begin to heal and move forward as productive women in society, nurses can make a difference in these women's lives. N ursing care actions designed to facilitate healing, such as providing a safe environment in which to voice their concerns, listening, comforting, caring in a compassionate and culturally congruent manner (Leininger, $1991 ; 1995)$ and communicating with empathy, could offer the potential for improved health and well being for these women and their children. This care requires an understanding, not only of the fundamental nature of addiction as a disease process, but also of the overwhelming feelings of guilt and shame experienced by substancedependent women, such as the African American women participants in this study. JNS

\section{R eferences}

Battle, S. (1990). M oving targets: Alcohol, crack, and Black women. In E.C. W hite (Ed.), T he Black women's health book: Speaking for ourselves. Seattle, WA: Seal Press.

Blume, S.B. (1990). Chemical dependency in women: Important issues. American Journal of Drug and Alcohol Abuse, 16(3\& 4), 297-307.

Boyd, C., \& G uthrie, B. (1996). Women, their significant others, and crack cocaine. The A merican Journal on Addictions, 5(2), 156-166. 
Boyd, C., H enderson, D., Ross-D urow, P., \& Aspen, J. (1997). Sexual trauma and depression in African American women who smoke crack cocaine. Substance Abuse, 18(3), 133-141.

Collins, P.H . (1991). Black feminist thought. N ew York: Routledge.

Ettorre, E. (1992). Women and substance use. New Brunswick, N J: Rutgers University Press.

Freire, P. (1990). Pedagogy of the oppressed. N ew York, NY: The Continuum Publishing Company.

H artwell, S.W. (1998). Treatment-seeking patterns of chronic recidivists. Q ualitative H ealth Research, 8(4), 481-494.

H atton, D.C. (1997). M anaging health problems among homeless women with children in a transitional shelter. Image: Journal of N ursing Scholarship, 29(1), 33-37.

Henderson, D., \& Boyd, C. (1997). All my buddies was male: Relationship issues of women with addictions. Journal of Gynecological and N eonatal $\mathbf{N}$ ursing, 26(4), 469-476.

Kearney, M.H., M urphy, S., \& Rosenbaum, M. (1994). M othering on crack cocaine: A grounded theory analysis. Social Science M edicine, 38(2), 351-361.

Klee, L., Schmidt, C., \& Ames, G. (1991). Indicators of women's al cohol problems: What women themselves report. The International Journal of the Addictions, 26(8), 879-895.

Leininger, M .M . (1991). The theory of culture care diversity and universality. In M .M . Leininger ( $E d$.$) , C ulturecarediversity \& universality: A theory of nursing$ (5-72). N ew York: N ational League for N ursing Press.

Leininger, M .M . (1995). Transcultural nursing: Concepts, theories, research and practices. N ew York: M cG raw-Hill.

Llorente Del Pozo, J.M., Gomez, F. C., Fraile, G.M., \& Perez, V.I. (1998). Psychological and behavioral factors associated with relapse among heroin abusers treated in therapeutic communities. Addictive Behaviors, 23(2), 155169.

M ontilus, G. (1989). Dompim: The spirituality of African peoples. N ashville, TN : Winston-Derek.

M orse, J.M ., Penrod, J., \& H upcey, J.E. (2000). Q ualitative outcome analysis: Evaluating nursing interventions for complex clinical phenomena. Journal of N ursing Scholarship, 32, 125-130.

M ynatt, S. (1998). Increasing resiliency to substance abuse in recovering women with comorbid depression. Journal of Psychosocial N ursing, 36(1), 28-36.

Public H ealth Service. (1985). Women's health: Report of the Public Health Service Task Force on Women's H ealth Issues. Washington, DC: D epartment of $\mathrm{H}$ ealth and $\mathrm{H}$ uman Services.

Rosenbaum, M. (1981). Sex roles among deviants: The woman addict. The International Journal of the Addictions, 16(5), 859-877.

Rowe, D., \& G rills, C. (1993). A frican centered drug treatment: An alternative conceptual paradigm for drug counseling with A frican A merican clients. Journal of Psychoactive Drugs, 25(1), 21-33.

Spradley, J.P. (1979). The ethnographic interview. Fort Worth, TX: H arcourt Brace Jovanovich College Publishers.

Valentich, M . (1982). Women and drug dependence. Journal of Alcohol and D rug Education, 28(1), 12-17.

Wellisch, D., \& Steinberg, M . (1980). Parenting attitudes of addicted mothers. The International Journal of the Addictions, 15, 806-819.

White, J.L., \& Parham, T.A. (1990). The psychology of Blacks: An African American perspective (2nd ed.). Englewood Cliffs, N J: Prentice H all.

Woodhouse, L.D. (1990). An exploratory study of the use of life history methods to determine treatment needs for female substance abusers. Response, 13(3), 12-15. 